\title{
Divulging vital research information before patent filing: Suicidal
}

\author{
Gayathri Vishwanath Patil ${ }^{\star}$
}

*Department of Pharmaceutics Global College of Pharmacy, Kahnpur Khui, Tehsil Anandpur Sahib, Distt. Ropar, Punjab, India

\begin{abstract}
Researchers and academicians for various reasons find themselves in a situation of divulging more than required and being deprived of recognition and benefit that they deserved. This paper briefly looks into the various advantages associated with patents, what could be the different reasons for sharing or going in public about the vital reason information before filling a patent. This paper also points to the extent one can share the information which would not siphon off "obviousness" essential for patentability. The paper discusses how both the objectives of sharing information, getting peer recondition and also not to lose a patent is been discussed.
\end{abstract}

Key words : information sharing methods, objectives, patent, novelty, non-obviousness, career, research.

\section{INTRODUCTION}

We are living in a highly sophisticated and well connected global world, which is experiencing and modulating over the influences, on all the areas of human endeavor. No human achievements are in geographic confinement or territorially marginalized. Patents laws and compliance to it has also gone global and hence is no exception to this global phenomenon. In this patent era, benefits are reaped only by those countries that have their global share of patents. Many times, a potential patent is often met with suicide due to premature sharing of vital information by various means with others, bringing the information in the public domain and thus siphoning away the essential component "novelty" and "non-obviousness" required for obtaining a patent. This also prevents the very benefits of patent reaching the society ${ }^{1}$, defeating its very purpose of research. Why this happens? How this situation could be avoided? The ways and means are being discussed here, so that such researchers do not end up in such a self-pitiable situation.

\section{History of Patents}

The first evidence ${ }^{2}$ of patent dates back to 500 BC to ancient Greek city of Sybaris. It was granted as an encouragement to those who would discover any new refinement in luxury. The profits made out of such methods would then be secured to only those inventors for certain period of time. It is believed that the first informal system of patenting $^{3}$ was developed in Renaissance Italy and was introduced into the rest of Europe by émigré Venetian glass-blowers to protect their skills against those of local workers. The first recorded patent ${ }^{3}$ was granted to John of Utynam in 1449 for a period of 20 years for a glass-making process previously unknown in England; in return of teaching his process to native Englishmen.

\section{What is a Patent?}

The word patent ${ }^{3}$ comes from the Latin 'litterae patentes', meaning an open letter, used by medieval monarchs with royal seal, to confer sole rights and privileges to be served as proof of those rights, for all to see. A patent ${ }^{4}$ is an exclusive, legal right granted by
Submission Date :22/06/2014 Revision Date : :22/09/2014 Accepted Date : :3/12/2014

DOI: $10.5530 /$ ijper.49.2.2 Correspondence Address Dr. Gayathri V. Patil Global College of Pharmacy, Kahnpur Khui,

Tehsil Anandpur Sahib, Distt. Ropar, Punjab, India.

Telephone:01887-242485

Fax:01887-242486

Email: patilgayathri@yahoo. co.in

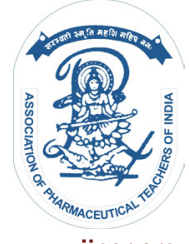

www.ijper.org 
the government of any country to an inventor to manufacture, use, or sell an invention for a limited number of years from the time it is registered. It entitles the patentee to solely monopolize and exploit the invention on the basis of making the invention public. The rationale ${ }^{5}$ behind granting a patent is to (i) reward the innovator some exclusivity - which could have been otherwise remained as a trade secrete (ii) encourage - who otherwise would not have bothered to invent it in the first place and (iii) promote the development of technology.

\section{What is Patentable?}

An invention is a type of intellectual property- that is, a product of original, creative thought. If an invention has not yet been publicly disclosed or recorded as unique, it might be eligible for legal protection in the form of a patent. Any of the following can be patentable: (i) process, (ii) machines, (iii) manufactures, (iv) compositions of matter and (v) improvements of any of the (i) to (iv). In order to deserve a patent, the invention should have (i) novelty ${ }^{6}-$ the matter disclosed in the specification is not published anywhere before the date of filing the patent application, (ii) inventive step ${ }^{6}$ it is not obvious to a person skilled in the art in the light of the prior publication / knowledge / document and (iii) industrially applicable - it should possess utility, so that it can be made or used in an industry.

\section{Advantages of Patents}

Majority of the patents comes from research labs and academic institutions. The advantages ${ }^{7}$ associated with patents for these institutions would be

(i) For Academic Institutions/ R\&D Departments / University: To provide an opportunity to have a positive impact on products and the marketplace.

(ii) For the Industrial Community: To address the need of private-for-profit sectors, the means to tap significant work of new discovery found in the academic lab.

(iii) For the General Public: To deliver the benefit from extraordinary new advances being made by the brightest minds.

(iv) To provide an additional quantitative indicator to assess the quality and quantity of university scientific work by the peers.

(v) Give private investors convincing evidence that the dollars they spend on academic research and development are yielding results.

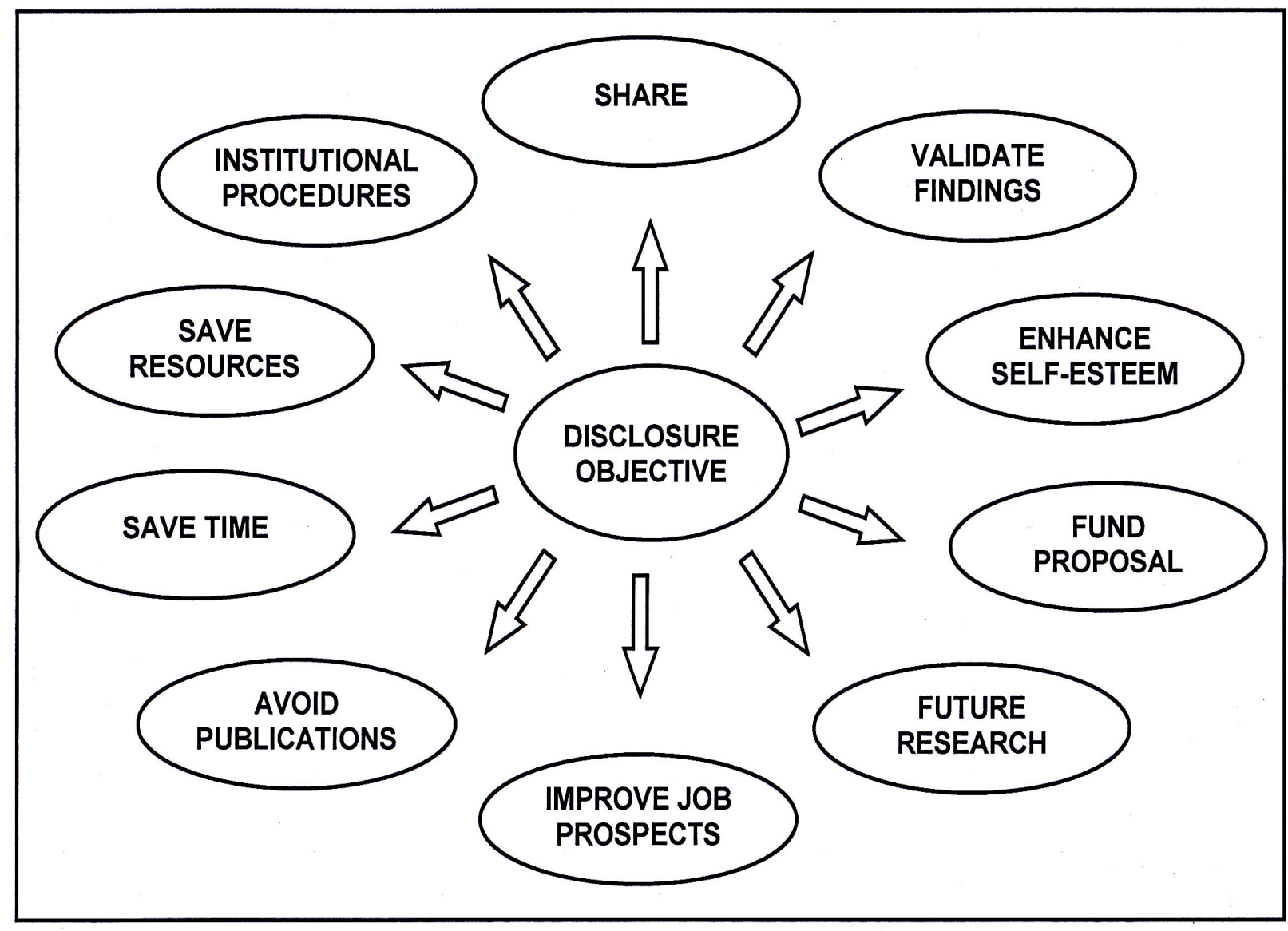

Figure 1: Objectives of disclosing information. 


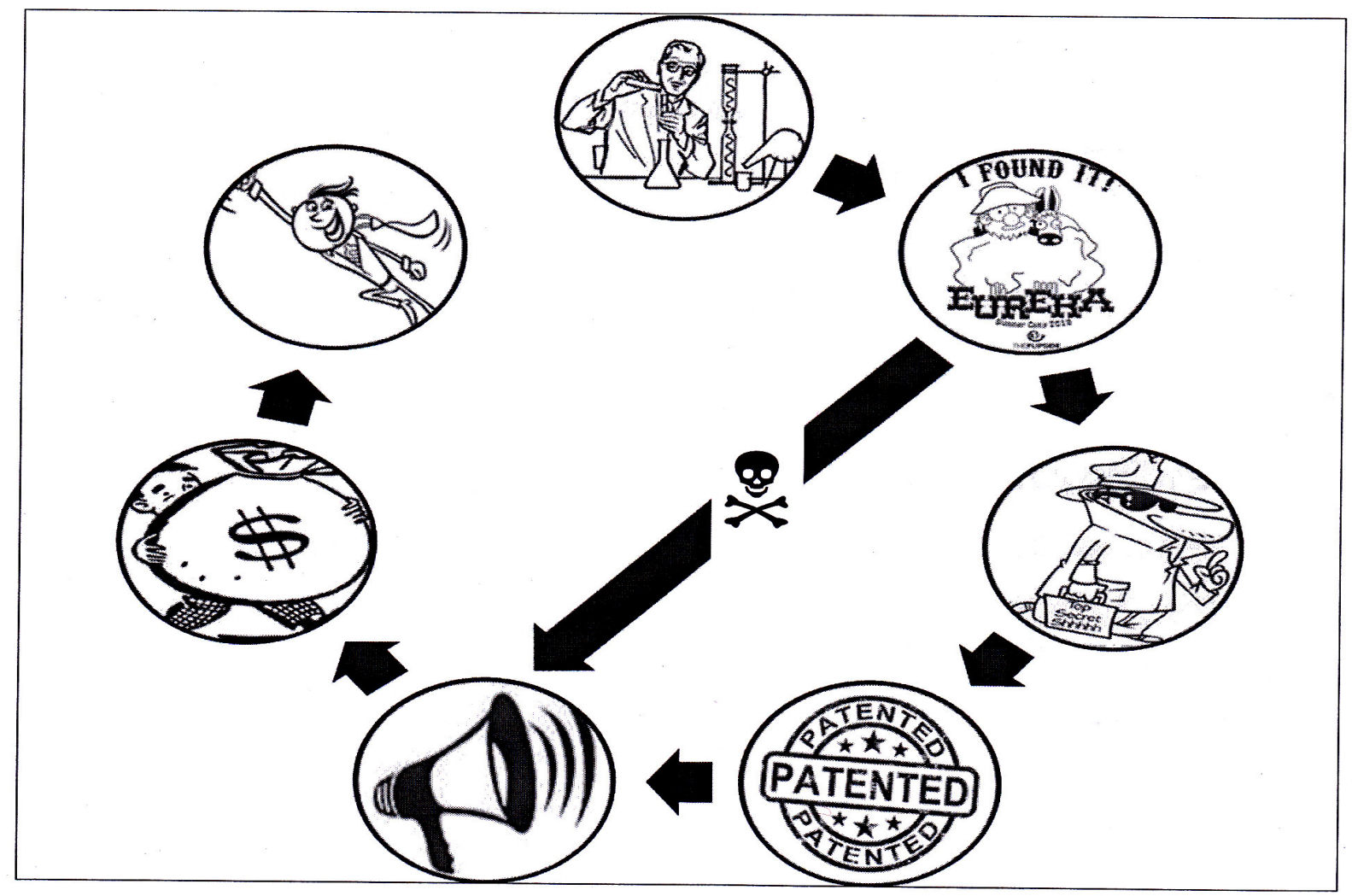

Figure 2: Ways of losing a patent novelty by sharing information.

(vi) Unlike publishing, a tangible valuation can be applied so that it that can be compared equally with other patents on a global scale.

\section{Objective of Research Publications and Sharing Research Findings}

The motives ${ }^{1,8}$ behind researchers disseminating their research findings is shown in Figure 1. It could be one or combinations of the following (i) desire to pass on their findings to those who may be interested, (ii) register ones claim to the work done and to gain peer esteem, (iii) seek rewards that may flow from that, (iv) meet the requirements of funding agencies, institutional guidelines, or pressure from coauthors or collaborators, (v) allow colleagues to criticize research, therefore potentially giving it validity, (vi) to use it as a basis for future research, (vii) for sense of achievement and satisfaction, (viii) to enhance job or promotional prospects, (ix) procedures of an institution to engage in the free exchange of information to evaluate the progress made by research students at student seminars, (ix) a good research enterprise whereby colleagues would learn new techniques, gain insights, and not repeat experiments that are not fruitful, wasting valuable resources. Industry has a general policy of not to publish their research during research or even after patent is obtained.

\section{Disadvantages of Research Publications and Sharing Research Findings}

Patents are not created in isolation but at places of learning, work places - be it labs, offices, institutions, homes, offices, fields etc. Before a patent concept consolidates completely in the creative and inquisitive mind of a researcher, it is very often or sometimes, prematurely shared in pieces or in entirety through (i) publication in books, professional journals, (ii) conferences presentations - abstracts, poster \& oral presentations, proceedings and questioning rounds (iii) invited lectures, seminars and (iv) web based social networking, (v) thesis and dissertations, (vi) discussions with industry, (vii) fellow researchers who are not involved in the research etc. and for the reasons cited above. Also, shown graphically in Figure 2.

Once the vital information of an invention comes in the public domain, it loses the essential component of being "novel" and losses the potential of being patentable, siphoning off the benefits which it otherwise possessed, if the same could have been first patented and then published, leading not only to personal loss but also possibly delaying/depriving it's benefit to the society; because now the industry would think of whether to venture its resources amidst "loss of exclusivity" and face the risk of competition in the market. This also 


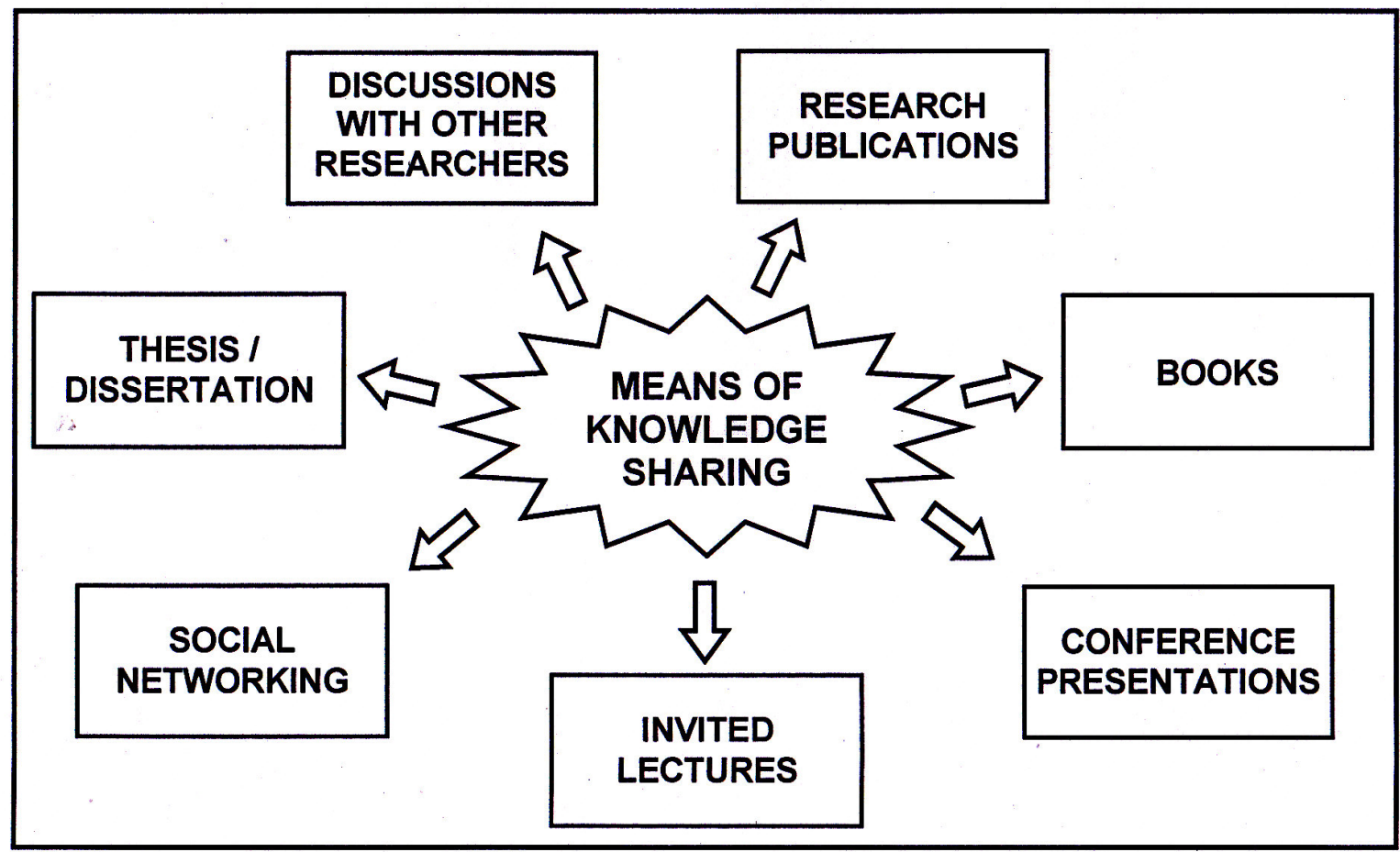

Figure : 3 Wise way

reduces $^{7}$ the possibility of collaborative partnerships of the inventor with the industry that would help him move new discoveries from the laboratory to the marketplace or in technology transfer. A comic version of wise pathway is given in Figure 2.

\section{Ways of Dissemination Vital Information and Means of Protecting}

The various activities indulged in by academicians / researchers ${ }^{9}$ before indulging in filing of the patent that would let go the vital information in public domain, nullifying the chances of patenting, Figure 3. However, in US $^{9}$, inventor gets 12 months of grace period from time of sharing the information to filing the patent while stands no good in other countries. So, if the patentee wants to share his research findings for the reasons cited above, due diligence has to be exercised at various levels as cited below.

\section{Abstract}

These are required to be submitted before a meeting, while submitting papers to be presented (orally or poster) in conferences, symposia and seminars, in appraisal submitting reports to the funding agencies etc. The abstract may often be published in proceedings or put on the web site. Hence, it's better not to divulge vital information in the abstract but just keep to very general information of the presentation to be made.

\section{Poster Presentation}

The content again has to be skillfully displayed, only in the conference. If possible, avoid giving printed handouts to delegates. Remain specific in answering questions. Do not divulge details. Answer to specific question. If answering questions are found reveal vital information, it's perfectly fine to get oneself excused for not being able to discuss the answer in full details at that point of time.

\section{Oral Presentations}

Same as poster presentations.

\section{Journal Submission for Peer Review and Possible Publications}

Its okay if the peer reviewer gets to know the vital information, as he is required to sign confidentially agreements and is expected not to divulge the information and this is not under public disclosure.

\section{Print Journals}

It's in public domain. The pre-print edition of the Journal is circulated on the web before the print edition. This means, the vital information is expeditiously brought in the public domain, which the inventor might not have been anticipated. To avoid such a situation, the inventor has to state that the paper contains potentially valuable invention in the applicable section of the publication clearance form while submitting manuscript. 


\section{Electronic Journal}

Same is applicable as for print journals.

\section{Unpublished Data}

Data in Thesis and Dissertations is generally assumed to be 'unpublished' by academician as it has not been submitted to a peer-reviewed journal for publication. However, the USPTO consider it as 'printed publications', accessible to the public, and are therefore a public disclosure as of the date the material was indexed as available on a Library shelf. Recently, even few of the Indian universities and university departments are following these practices of indexing the material.

\section{CONCLUSIONS}

Research publication before filing patent defeats the very purpose of use of research facilities and resources, faculties involved, time invested in this evolved system of patent era. We should know that if service of any kind, be it through ideas or work, if has reached the masses; it is through capitalized channels of production and commercialisation. Hence, it's better to "protect, patent, publish and survive" rather than to "publish and perish" in the present thriving regime of compulsive commercial patent regime.

\section{CONFLICTS OF INTEREST}

There is no conflict of interest.

\section{ACKNOWLEDEGEMENT}

The author thanks the Global College of Pharmacy, Kahnpur Khui for the moral support.

\section{REFERENCES}

1. Surana R. Patent, In: Bencil presents protect your ideas, Scinnovation Consultants Pvt. Ltd. ISBN 978-81-92381404, $1^{\text {st }}$ Ed. 2012.

2. Charles Anthon. A Classical Dictionary: Containing An Account of the Principal Proper Names Mentioned in Ancient Authors, And Intended To Elucidate All The Important Points Connected With The Geography, History, Biography, Mythology, And Fine Arts of The Greeks And Romans Together with an Account of Coins, Weights, And Measures, With Tabular Values Of The Same, Harper \& Bros, 1841, page 1273.

3. Intellectual property \& sciences, Accessed from http://ip-science. thomsonreuters.com/support/patents/patinf/patentfaqs/history/ on 22.02.2014.

4. Patent, Accessed from http://dictionary.reference.com/browse/patent. 22.02.2014

5. Drysdale D. Ethics and patents: are patents bad or just misunderstood, Patent Updates. Drug Discovery Today 2004; 3(6): 253-4. 